D. Hanimyan, B.Sc., Mr. J. Fabenyi, R. T., B.Agr., and Mr. M. Khan, for their expert technical assistance. The authors are grateful to the Medical and Nursing Staff of the Neonatal Unit of the Hospital for Sick Children for their help and co-operation.

48. This investigation was in part supported by the Medical Research Council of
Canada (Grant MA 4635)

49. Requests for reprints should be addressed to: 1. C. Radde, M.D., Research Institute, The Hospital for Sick Children, 555 University Ave., Toronto 2 (Canada)

50. Accepted for publication April 2, 1975

\title{
The Determination of Hypoxanthine and Xanthine with a $\mathrm{Po}_{2}$ Electrode
}

\author{
O. D. SAUGSTAD ${ }^{(18)}$ \\ Perinatal Research Unit, University Hospital, Uppsala, Sweden
}

\section{Extract}

A simple and rapid method for determination of the hypoxanthine and xanthine concentration in plasma and urine is described. The method is based on the principle that oxygen is consumed quantitatively when hypoxanthine and xanthine are oxidized to urate by xanthine oxidase. By using Henry's law a direct measure of the hypoxanthine and xanthine concentration is obtained.

The method determines these oxypurines in volumes of $200 \mu \mathrm{l}$ in concentrations less than $5 \mu \mathrm{mol} /$ liter in about $5 \mathrm{~min}$. The average precision in the range of $0-50 \mu \mathrm{mol} /$ liter is $2.6 \mu \mathrm{mol} /$ liter. Of the added hypoxanthine, $99-102 \%$ is recovered in plasma. Even though xanthine oxidase is a rather nonspecific enzyme, experiments show that this method is highly specific during physiologic conditions.

\section{Speculation}

Other purines which can be metabolized to hypoxanthine can be determined by this method. For instance, inosine, which is metabolized to hypoxanthine by nucleoside phosphorylase in the presence of phosphate, might also be determined according to this method.

The spectrophotometric method of Kalckar (10) represented an important step in the determination of the purine metabolites, hypoxanthine and xanthine. The principle of this method was employed together with further developments of $\mathrm{J} \phi$ rgensen $e t$ al. (8), and Brandt Petersen et al. (3). In addition there are also chromatographic and isotope methods available for determination of these oxypurines (13).

However, all of these methods are unsuitable for routine determination because they are time consuming, demand large volumes of blood, and are inaccurate for the detection of the low concentrations of oxypurines found in human plasma.

Berne (1) showed that there is an increased level of inosine and hypoxanthine in coronary venous blood from the ischemic myocardium of cat and dog. Crowell et al. (5) showed that dogs lose their purines irreversibly during hemorrhagic shock. Saugstad (12) showed that the oxypurine level in umbilical cord plasma is increased in newborn infants with clinical signs of intrauterine hypoxia.

Collectively, these results indicate the need for a simple, reliable, rapid method for the measurement of oxypurines in the low concentrations found in human plasma. The present report describes such a method.

\section{THEORY}

Hypoxanthine is oxidized to urate via xanthine by xanthine oxidase. Figure 1 shows that oxygen is consumed during the reaction. If all the hydrogen peroxide formed during the reaction is split into water and oxygen, there is a quantitative relation between consumed oxygen and metabolized hypoxanthine and xanthine, respectively. Thus, $1 \mathrm{~mol}$ oxygen is consumed $/ \mathrm{mol}$ hypoxanthine metabolized, and $0.5 \mathrm{~mol}$ oxygen is consumed $/ \mathrm{mol}$ xanthine oxidized to urate.

By measuring the decrease of $\mathrm{P}_{\mathrm{O}_{2}}$ of the solution after addition of xanthine oxidase, a quantitative measure of the oxypurine concentration is obtained. It is presupposed that all of the oxypurines are metabolized to urate. The following equation is then valid.

$$
\begin{aligned}
& \text { Hypoxanthine }+\mathrm{O}_{2}=\text { urate } \\
& \text { Xanthine }+1 / 2 \mathrm{O}_{2}=\text { urate }
\end{aligned}
$$

\section{CALCULATIONS}

Henry's law states that $\mathrm{dP}=\mathrm{KdC}$, where $\mathrm{dP}$ is the change in partial pressure of a gas in solution where the concentration of the gas is changed $\mathrm{dC}$. $\mathrm{K}$ is a constant depending upon the solution, among other things. If $\mathrm{K}$ is known, $\mathrm{dC}$ can be calculated if $\mathrm{dP}$ is measured.

It follows that

$$
\mathrm{K}=\frac{\mathrm{P} \cdot \mathrm{Mw}}{\mathrm{V} \cdot \mathrm{S}}
$$

$\mathrm{P}$ is the partial pressure of the gas in the solution. Mw is the molecular weight of the gas, $V$ is the volume of gas dissolved per liter of solution, and $\mathrm{S}$ is the specific density of the gas.

In 1 liter of plasma at $38^{\circ}$ and $760 \mathrm{~mm} \mathrm{Hg}$ of oxygen, $24 \mathrm{ml}$ oxygen are dissolved. (The volume corrected to standard pressure and temperature (14)). The specific density of oxygen (micrograms per microliter) at standard temperature and pressure is 1.429 (6). The molecular weight of oxygen is 32 . The constant $\mathrm{K}$ for oxygen dissolved in plasma is therefore

$$
\mathrm{K}=\frac{760.32 \mathrm{~mm} \mathrm{Hg}}{24,000 \cdot 1,429 \mu \mathrm{mol} / \text { liter }}=0.71=\mathrm{mm} \mathrm{Hg} / \mu \mathrm{mol} / \text { liter }
$$




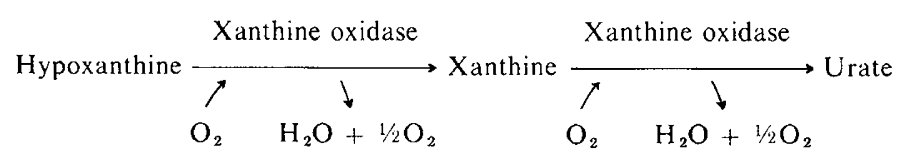

Fig. 1. The catabolism of hypoxanthine to urate via xanthine. Oxygen is consumed in the presence of xanthine oxidase.

In a solution containing only hypoxanthine or xanthine the concentration of hypoxanthine $(\mathrm{Hx})$ and xanthine $(\mathrm{X})$, respectively, is

$$
\begin{aligned}
& (\mathrm{Hx})=\frac{\mathrm{dP}_{\mathrm{O}_{2}}}{0.71} \mu \mathrm{mol} / \text { liter } \\
& (\mathrm{X})=\frac{2 \cdot \mathrm{dP}_{\mathrm{O}_{2}}}{2 \cdot 0.71} \mu \mathrm{mol} / \mathrm{liter}
\end{aligned}
$$

Both hypoxanthine and xanthine are present in biologic fluid. By the use of this principle one cannot separate these two metabolites. To separate these two metabolites it is necessary also to measure the increase of the urate concentration, $d U$, in the solution after addition of xanthine oxidase. It then follows that

Hence

$$
\begin{aligned}
& 0.71 \cdot(\mathrm{Hx})+1 / 20.71(\mathrm{X})=\mathrm{d} \mathbf{P}_{\mathrm{O}_{2}} \\
& \mathrm{dU}=(\mathrm{Hx})+(\mathrm{X})
\end{aligned}
$$

$$
\frac{(X)}{(X)+(H x)}=\frac{(X)}{d U}=\frac{2 d U-2 d P_{\mathrm{O}_{2}} / 0.71}{d U}
$$

The concentrations of oxypurines in plasma are normally so low that it is aimless to separate hypoxanthine and xanthine. In the routine it is more practical to overlook xanthine and calculate as if all the oxypurines were hypoxanthine. Assuming a xanthine to hypoxanthine ratio ranging from $0.25-0.5(4)$ the error produced is $12-25 \%$.

By contrast, in the urine the oxypurine level is so high that it is possible to separate the two metabolites.

\section{MATERIALS AND METHODS}

Standard solutions of hypoxanthine were prepared from reagents obtained from Sigma Chemical Co. Xanthine oxidase with activity of approximately $0.4 \mu / \mathrm{mg}$ and catalase with activity of approximately $50,000 \mu / \mathrm{mg}$ were obtained from Boehringer Mannheim. All assays were performed with phosphate buffer (50 $\mathrm{mM}, \mathrm{pH}$ 7.4).

\section{APPARATUS AND PROCEDURE}

A Radiometer $\mathrm{P}_{\mathrm{O}_{2}}$ electrode $(\mathrm{E} / 5046 / 0)$ linked to a Radiometer $\mathrm{pH}$ meter 27 was used. The $\mathrm{P}_{\mathrm{O}_{2}}$ electrode was placed in a chamber made for capillary $\mathrm{P}_{\mathrm{O}_{2}}$ determinations (Fig. 2). The chamber was thermostated at $37^{\circ}$ and all solutions were placed in a water bath of $37^{\circ}$. To each milliliter of solution, $20 \mu$ l catalase were added. The solution (plasma, urine, cerebrospinal fluid, amniotic fluid, etc.) was injected into the chamber with a syringe, avoiding air bubbles. The initial $\mathrm{P}_{\mathrm{O}_{2}}, \mathrm{Pi}_{\mathrm{O}_{2}}$ was noted, and the solution withdrawn. Ten microliters of xanthine oxidase were then added with a $10-\mu 1$ Hamilton syringe to the bottom of the chamber. The solution was then injected carefully into the chamber, and the final $\mathrm{P}_{\mathrm{O}_{2}}, \mathrm{Pe}_{\mathrm{O}_{2}}$ measured at the completion of the reaction. The difference between $\mathrm{Pi}_{\mathrm{O}_{2}}$ and $\mathrm{Pe}_{\mathrm{O}_{2}}, \mathrm{dP}_{\mathrm{O}_{2}}$ was used to calculate the hypoxanthine concentration in the solution. Urate was determined by a routine spectrophotometrical method.

\section{RESULTS}

Changes in plasma hypoxanthine concentrations with time in blood maintained at $+4^{\circ}$ are shown in Figure 3. One milliliter of the blood sample was centrifuged at 30,60, and $120 \mathrm{~min}$, etc., and the hypoxanthine concentration of the plasma was determined. In the course of $30-60 \mathrm{~min}$ concentrations decreased to zero; after $2-4 \mathrm{hr}$ the hypoxanthine increased rapidly. This increase has also been observed by others (9). The same pattern is also ob-

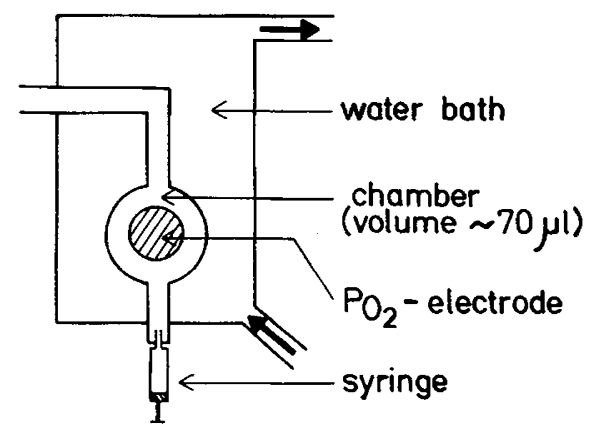

Fig. 2. Chamber with $\mathrm{P}_{\mathrm{O}_{2}}$ electrode. The solution is injected with a syringe into the chamber. The volume of the chamber is approximately 70 $\mu \mathrm{l}$ and the dead space $30-40 \mu \mathrm{l}$. Hence the minimal volume required is $100-110 \mu 1$.

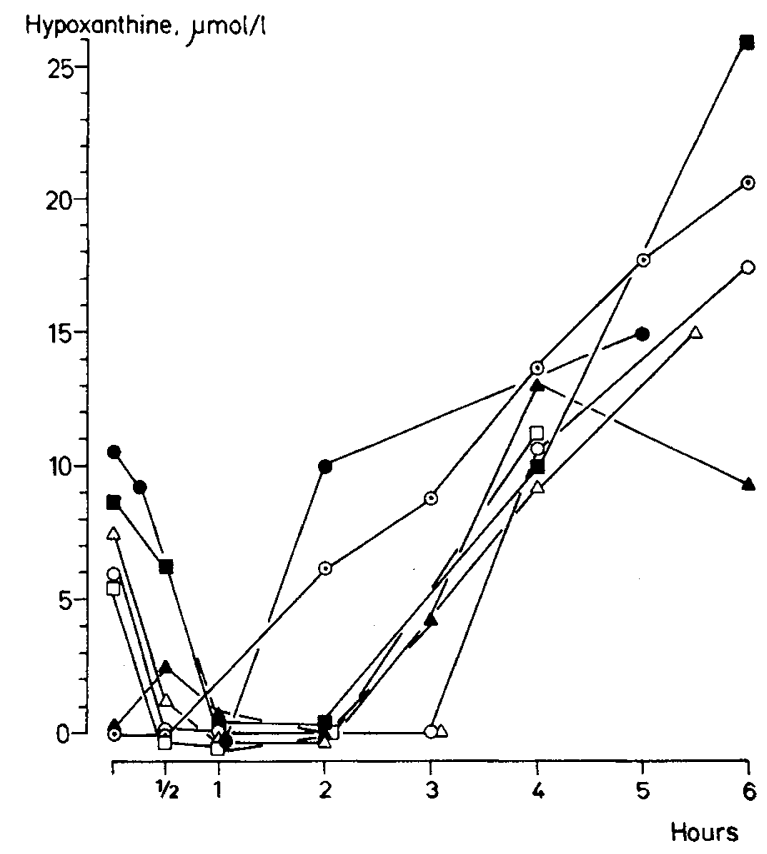

Fig. 3. Change of hypoxanthine concentration in plasma of blood placed in $+4^{\circ}$. Complete blood is placed at $+4^{\circ} \mathrm{C}$. At $30,60,120$ min, etc. 1.0 $\mathrm{ml}$ blood is centrifuged and the hypoxanthine concentration of the plasma is determined. The blood in the refrigerator is shaken regularly.

served in blood at room temperature. It is necessary to separate the plasma immediately in order to avoid erroneous results.

Figure 4 shows the measurements of standard solutions of hypoxanthine $(5,10,25$, and $50 \mu \mathrm{mol} /$ liter $)$. Ten measurements were performed for each solution. The $\mathrm{K}$ for this solution was calculated by regression analysis to 0.8 . This differs, as expected, slightly from $\mathrm{K}$ of plasma. The figure shows that hypoxanthine can be measured at concentrations of $5 \mu \mathrm{mol} /$ liter with good accuracy.

\section{SPECIFICITY}

To test the specificity of the method, several substances which theoretically could interfere with one measurement were added to plasma with known concentration of hypoxanthine.

Table 1 shows the results of hypoxanthine measurements in plasma after the addition of inosine, guanosine, adenine, and acetaldehyde. The results represent the mean of three measurements and were compared with hypoxanthine measurements of the same plasma with added phosphate buffer as control. Inosine and guanosine did not interfere in the concentrations tested. Adenine and acetaldehyde interfered only at very high concentrations.

\section{RECOVERY}

Table 2 gives the results of recovery of hypoxanthine added to 


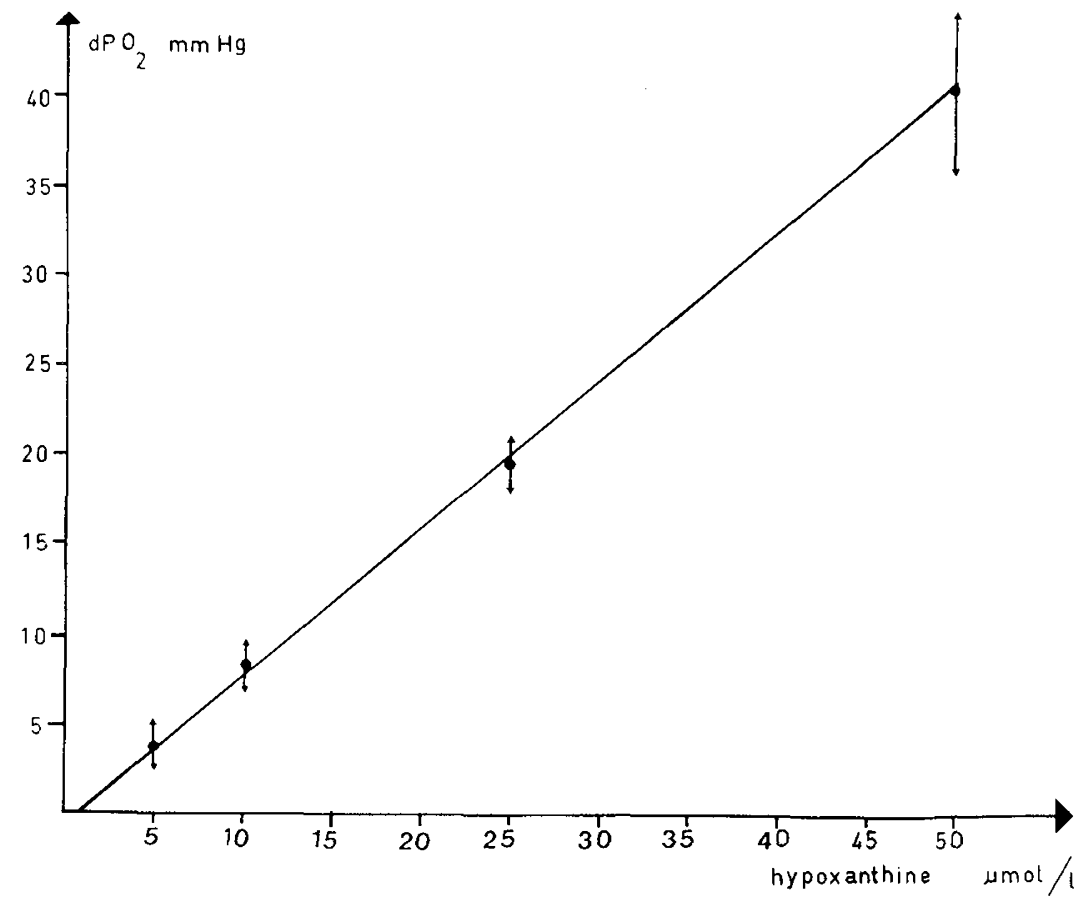

Fig. 4. A standard curve for hypoxanthine determinations in phosphate buffer is drawn. Ten measurements were made on standard solutions of hypoxanthine with concentrations of $5,10,25$, and $50 \mu \mathrm{mol} /$ liter. The regression line was calculated as $\mathrm{dP}_{\mathrm{O}_{2}}=0.8 \mathrm{Hx}-0.3$. $\mathrm{dP}_{\mathrm{O}_{2}}$ is the decrease in $\mathrm{P}_{\mathrm{O}_{2}}$ in $\mathrm{mm} \mathrm{Hg}$ during the reaction; and $\mathrm{Hx}$ is the hypoxanthine concentration in micromoles per liter.

Table 1. Specificity: Addition to plasma of inosine, guanosine, adenine, and acetaldehyde

\begin{tabular}{lcc}
\hline \multicolumn{1}{c}{$\begin{array}{c}\text { Substance added } \\
\text { to plasma }\end{array}$} & $\begin{array}{c}\text { Hypoxanthime } \\
\text { in plasma, } \\
\mu \mathrm{mol} / \mathrm{liter}\end{array}$ & $\begin{array}{c}\text { Hypoxanthine } \\
\text { in reference, } \\
\mu \mathrm{mol} / \text { liter }\end{array}$ \\
\hline Inosine, $100 \mu \mathrm{mol} / \mathrm{liter}$ & 9.0 & 8.0 \\
Guanosine, $100 \mu \mathrm{mol} / \mathrm{liter}$ & 6.5 & 7.5 \\
Adenine, $20 \mathrm{mmol} / \mathrm{liter}$ & 40 & 10.5 \\
Adenine, $400 \mu \mathrm{mol} /$ liter & 20.5 & 18.5 \\
Acetaldehyde, $1.8 \mathrm{~mol} /$ liter & 200 & 4.5 \\
Acetaldehyde, $1.8 \mathrm{mmol} /$ liter & 13.5 & 13.0 \\
\hline
\end{tabular}

${ }^{1}$ To $0.5 \mathrm{ml}$ plasma was added $0.2 \mathrm{ml}$ of the substance; to $0.5 \mathrm{ml}$ of the same plasma was added $0.2 \mathrm{ml}$ buffer. This was used as reference plasma. Each result given in the table is the mean of three measurements.

Table 2. Recovery of added hypoxanthine to plasma ${ }^{1}$

\begin{tabular}{|c|c|c|c|}
\hline \multicolumn{2}{|c|}{$\begin{array}{c}\text { Plasma with initial } \\
\text { hypoxanthine }(0 \mu \mathrm{mol} / \text { liter })^{2}\end{array}$} & \multicolumn{2}{|c|}{$\begin{array}{c}\text { Plasma with initial } \\
\text { hypoxanthine }(25 \mu \mathrm{mol} / \mathrm{liter})^{3}\end{array}$} \\
\hline Added, nmol & Recovered, $\mathrm{nmol}$ & Added, nmol & Recovered, nmol \\
\hline 19 & 28 & 20 & 28 \\
\hline 40 & 34 & 29 & 27 \\
\hline 62 & 62 & 60 & 53 \\
\hline
\end{tabular}

'Of a standard solution of hypoxanthine with known hypoxanthine concentration, $0.5 \mathrm{ml}$ was added to $0.5 \mathrm{ml}$ plasma. The hypoxanthine concentration in this plasma was determined and the amount of recovered hypoxanthine was calculated. Two different plasmas was used. One with initial hypoxanthine concentration of $0 \mu \mathrm{mol} / \mathrm{liter}$ and the other with 25 $\mu \mathrm{mol} / \mathrm{liter}$. Each result given in the table is the mean of three measurements.

${ }^{2}$ Recovered: $102.5 \%$

${ }^{3}$ Recovered: $99 \%$. plasma. Plasma with a hypoxanthine concentration of $0 \mu \mathrm{mol} /$ liter and $25 \mu \mathrm{mol} /$ liter, respectively, was used.

Hypoxanthine was then added in three different amounts to each of the plasmas. In each of these six solutions the hypoxanthine concentration was subsequently determined, and the amount of recovered hypoxanthine was calculated. Each result in Table 2 is the mean of three parallel measurements. The table shows that recovery ranges from $99-102 \%$.

To test how much hypoxanthine was recovered as urate, $0.2 \mathrm{ml}$ standard hypoxanthine solution was added to $1 \mathrm{ml}$ plasma. The concentration of hypoxanthine in the sample was then determined. To $1 \mathrm{ml}$ of the same plasma $0.2 \mathrm{ml}$ phosphate buffer solution was added as a reference. Twenty microliters of xanthine oxidase were then added to both of these samples, and the concentration of urate was determined in both of them. The difference of hypoxanthine concentration in the plasma to which hypoxanthine was added and the reference plasma was used to calculate the expected difference of urate, dUe, in the two samples. The dUe was then compared with the measured urate difference, $\mathrm{d} U$. This procedure was done with three different plasmas, and each result given in Table 3 is the mean of three measurements. The table shows good accordance between $\mathrm{dU}$ and $\mathrm{dU}_{\mathrm{e}}$. Of the added hypoxanthine, $95.5-108.8 \%$ is recovered as urate.

\section{PRECISION}

Table 4 gives the precision of the method in the range of $0-50$ $\mu \mathrm{mol} / \mathrm{liter}$. One standard deviation is given together with the coefficient of variation. The precision varies from $2.0-3.1 \mu \mathrm{mol} /$ liter with an average of $2.6 \mu \mathrm{mol} / \mathrm{liter}$.

\section{HYPOXANTHINE IN PLASMA}

In 10 healthy adults the hypoxanthine concentration ranged from $0-11 \mu \mathrm{mol} /$ liter. This is in accordance with the results of Klineberg et al. (11), who found a hypoxanthine level in four normal adults ranging from $4.8-12.5 \mu \mathrm{mol} /$ liter. However, Jørgensen et al. (8) reported concentrations ranging from 7-20 $\mu \mathrm{mol} /$ liter.

In umbilical cord plasma the hypoxanthine level in 29 infants with normal delivery ranged from $0-11 \mu \mathrm{mol} / \mathrm{liter}$. Ten of 12 
Table 3. Recovery of added hypoxanthine as urate

\begin{tabular}{cccccc}
$\begin{array}{c}\mathrm{Hx}, \\
\mu \mathrm{mol} / \mathrm{liter}\end{array}$ & $\begin{array}{c}\mathrm{U}_{1}, \\
\mathrm{mg} / 100 \\
\mathrm{ml}\end{array}$ & $\begin{array}{c}\mathrm{U}_{2}, \\
\mathrm{mg} / 100 \\
\mathrm{ml}\end{array}$ & $\begin{array}{c}\mathrm{dU}, \\
\mathrm{mg} / 100 \\
\mathrm{ml}\end{array}$ & $\begin{array}{c}\mathrm{dU} \\
\mathrm{mg} / 100 \\
\mathrm{ml}\end{array}$ & $\begin{array}{c}\text { Recovered, } \\
\%\end{array}$ \\
\hline 33.0 & 3.30 & 2.73 & 0.57 & 0.62 & 108.8 \\
34.0 & 2.90 & 2.23 & 0.67 & 0.64 & 95.5 \\
39.0 & 3.00 & 2.23 & 0.77 & 0.74 & 96.1 \\
\hline
\end{tabular}

${ }^{1} \mathrm{Hx}$ : hypoxanthine concentration of plasma with initial concentration of $0 \mu \mathrm{mol} /$ liter after the addition of hypoxanthine solution; $\mathrm{U}_{1}$ : urate concentration in plasma, added hypoxanthine and xanthine oxidase; $\mathrm{U}_{2}$ : urate concentration in plasma added buffer solution and xanthine oxidase; dU: $\mathrm{U}_{1}-\mathrm{U}_{2} ; \mathrm{dU}_{\mathrm{e}}$ : the expected urate difference if all the added hypoxanthine was recovered as urate after the addition of xanthine oxidase. Each result in the table is the mean of three measurements.

Table 4. Precision of method tested on different plasmas ${ }^{1}$

\begin{tabular}{cccc}
\hline $\begin{array}{c}\mathrm{Hx}, \\
\mu \mathrm{mol} / \text { liter }\end{array}$ & $\begin{array}{c}\text { 1 SD, } \\
\mu \mathrm{mol} / \text { liter }\end{array}$ & CV, \% & No. \\
\hline 0.0 & 2.2 & & 20 \\
15.0 & 2.0 & 12.0 & 16 \\
27.0 & 2.9 & 10.5 & 17 \\
44.0 & 3.1 & 6.5 & 14 \\
\hline
\end{tabular}

${ }^{1} \mathrm{Hx}$ : hypoxanthine concentration in plasma; $\mathrm{CV}$ : coefficient of variation; No.: number of measurements.

newborn infants with clinical signs of intrauterine hypoxia had increased values ranging from $10-60 \mu \mathrm{mol} / \mathrm{liter}(12)$.

\section{DISCUSSION}

The results of the present study describe a method for the measurement of oxypurine in plasma. There are several sources of error. For instance, the oxygen content of the solution could be changed during by the withdrawal of plasma from the chamber. It is therefore important to treat the solution very carefully during the withdrawal. It is also essential that the $\mathrm{Pi}_{\mathrm{O}_{2}}$ be as close as possible to the $\mathrm{P}_{\mathrm{O}_{2}}$ of the atmosphere. If the $\mathrm{Pi}_{\mathrm{O}_{2}}$ is less than atmospheric $\mathrm{P}_{\mathrm{O}_{2}}$ there will be a gradient between the solution and the air. Withdrawal of the solution will then increase the $\mathrm{P}_{\mathrm{O}_{2}}$ in the solution, and the value for $\mathrm{Pe}_{\mathrm{O}_{2}}$ will be too small, thus too low concentrations of hypoxanthine will be measured.

$\mathrm{Pe}_{\mathrm{O}_{2}}$ is determined when there is no more decrease of $\mathrm{P}_{\mathrm{O}_{2}}$. This might be difficult to decide since the electrode itself consumes oxygen. By using a recorder it is possible to determine $\mathrm{Pe}_{\mathrm{O}_{2}}$ by extrapolation and thus eliminate such error.

Free hemoglobin in the solution will also give values for hypoxanthine which are too low because of the binding of the oxygen. It is therefore important to avoid hemolysis in the blood samples.

In spite of these factors the precision of the method seems satisfactory. The method may not be precise enough at concentrations less than $5 \mu \mathrm{mol} /$ liter. On the other hand, since during hypoxia levels are commonly raised to concentrations greater than $10 \mu \mathrm{mol} / \mathrm{liter}$, the precision will be satisfactory and can be correlated with the pressure of hypoxia.

The enzyme xanthine oxidase is nonspecific (2). In addition to catalysing hypoxanthine and xanthine, it also catalyses chemical reactions of other purines such as, e.g., adenine. The adenine concentration is, however, normally negligible in body fluids. In addition, the velocity of the reaction is so slow that it is unlikely that this metabolite could interfere. Several aldehydes are also substrates for the enzyme (15). However, the Michaelis constant
$\left(\mathrm{K}_{\mathrm{m}}\right)$ of aldehydes ranges from $10^{-2}-10^{-3}$, whereas $\mathrm{K}_{\mathrm{m}}$ of purines are in the range of $10^{-6}$ (15). In addition, $\mathrm{V}_{\max }$ of, e.g., acetaldehyde, is reported to be 0.3 of that of hypoxanthine (2). This means that only very high concentrations of aldehydes might interfere with the hypoxanthine determinations. This is in accordance with the results of this work. The specificity of the method is therefore adequate during physiologic conditions. However, it is still not known if any drugs interfere with hypoxanthine determination. Ethanol, for example, is metabolized to acetaldehyde. 1-Methyl xanthine is also a substrate of the enzyme (13), and an increased level of this substance could interfere.

It is well known that several substances inhibit xanthine oxidase. Patients treated with xanthine oxidase inhibitors will therefore probably have lower values than normal, and any hypoxia could be difficult to diagnose with this variable. On the other hand, hyperuricemia, independent of etiology, will probably raise the hypoxanthine concentration in plasma and the rate of excretion in the urine.

Unpublished experiments of deVerdier and Saugstad (6) indicate that inosine is incorporated very quickly into the erythrocytes and partly transformed to hypoxanthine which is detected in the solution after only a few minutes. Therefore, it seems likely that what is actually being measured with this method is hypoxanthine plus inosine. The inosine level is normally so low compared with that of oxypurine that this error is negligible. On the other hand, the inosine level is increased during hypoxia and will therefore probably add to the hypoxanthine level.

\section{SUMMARY}

A method for the determination of the oxypurines, hypoxanthine and xanthine, is described. The method is based on the principle that oxygen is consumed when oxypurines are metabolized to urate by xanthine oxidase. This consumption is measured with a $\mathrm{P}_{\mathrm{O}_{2}}$ electrode.

Although xanthine oxidase is nonspecific, the method seems to be specific during physiologic conditions. The advantages of this method compared with established ones are that it is simple, rapid, and determines the metabolites with good precision in the low concentrations found in human plasma.

\section{REFERENCES}

1. Berne, R. M.: Cardiac nucleotides: Possible role in regulation of coronary flow. Amer. J. Physiol., 204: 317 (1963)

2. Booth, V. H.: The specificity of xanthine oxidase. Biochem. J., 32: 494 (1938).

3. Brandt Petersen, B., Jørni, J., and Jørgensen, S.: Separate enzymatic determination of hypoxanthine and xanthine in human urine. Scand. J. Clin. Lab. Invest., I7: 454 (1965)

4. Brandt Petersen, B., Jørni, J., and Jørgensen, S.: Hypoxanthine, xanthine and uric acid in human urine and in decomposed blood. Scand. J. Clin. Lab. Invest., 17: 460 (1965).

5. Crowell, J. M., Jones, C. E., and Smith, E. E.: Effect of allopurinol on hemorrhagic shock. Amer. J. Physiol., 216: 714 (1969).

6. DeVerdier, C. H., and Saugstad, O. D.: Unpublished experiments.

7. Handbook of Chemistry and Physics, Ed. 52, F-55, (The Chemical Rubber Co., Cleveland, 1971-1972).

8. Jørgensen, S., and Engelund Poulsen, H.: Enzymic determination of hypoxanthine and xanthine in human plasma and urine. Acta Pharmacol. Toxicol., II: 223 (1955).

9. Jørgensen, S., and Engelund Poulsen, H.: On accumulation of hypoxanthine plus xanthine in withdrawn human blood. Acta Pharmacol. Toxicol., 11: 207 (1955).

10. Kalckar, H. M.: Differential spectrophotometry of purine compounds by means of specific enzymes. J. Biol. Chem., 167: 429 (1947).

11. Klineberg, J. R., Goldfinger, S., Bradley, K. H., and Seegmiller, J. E.: An enzymatic spectrophotometric method for the determination of xanthine and hypoxanthine. Clin. Chim., 13:834 (1967).

12. Saugstad, O. D.: Purinemetabolites as a measurement of intrauterine hypoxia. 4. European Congress of Perinatal Medicine, Praha, 1974.

13. Weissmann, B., Bromberg, P. A., and Gutman, A. A.: The purine bases of human urine. J. Biol. Chem., 224: 407 (1957).

14. White, A., Handler, P., and Smith, E. L.: Principles of Biochemistry, Ed. 5, p. 835 (McGraw-Hill Book Company, New York, 1973).

15. Boehringer \& Soehne GmbH, Mannheim, Biochemische Abteilung: Xanthine oxidase (1964). 
16. This work was supported by the University of Uppsala and The Norwegian Research Council for the Science and Humanities.

17. Professor G. Rooth and Professor C. H. deVerdier, University Hospital Uppsala, have contributed with valuable ideas and support to this work.
18. Requests for reprints should be addressed to: O. D. Saugstad, M.D., Institute for Surgical Research, Rikshospitalet, Oslo I, Norway.

19. Accepted for publication March 13, 1975.

\title{
Growth and Skeletal Maturation in Asthmatic Children: Effect of Corticosteroid Treatment
}

\author{
HELEN G. MORRIS ${ }^{(25)}$ \\ Children's Asthma Research Institute and Hospital, and the National Jewish Hospital and Research Center, Denver, Colorado, USA
}

\section{Extract}

The effects of corticosteroid treatment on growth and skeletal maturation were evaluated in 189 children with severe asthma who were referred for care at a residential treatment center. Height age on admission was significantly retarded in $8-10 \%$ of patients who had received little corticosteroid treatment previously and in $35 \%$ of patients who had taken steroids daily for more than 2 years. Children who had been treated with steroids intermittently or on alternate days were comparable to those who had taken steroids rarely. During an average residential period of 17 months, patients whose daily steroid treatment was discontinued had a relative gain in height age of 5 months; children who were started on daily steroids had a 5-month delay in growth. Evaluation of skeletal maturation at the time of admission revealed that skeletal age was more retarded than height age in the boys and less retarded than height age in the girls. During the period of residence, the changes in bone age paralleled the changes in height age.

\section{Speculation}

Suppression of growth is a frequent complication in asthmatic children who receive prolonged treatment with corticosteroids. In some patients the suppression of growth may result in permanent dwarfism. However, no information is currently available on the adult heights of patients who have received prolonged corticosteroid therapy during childhood.

It is well known that prolonged corticosteroid therapy in children may be associated with the inhibition of growth. However, there are still a number of unanswered questions with respect to the frequency and severity of the dwarfism induced by corticosteroids, the possible contributory influence of the underlying disease, and the likelihood of "catch-up" growth after corticosteroid therapy is discontinued. Additionally, more information is needed about the effects of corticosteroid treatment on the skeletal maturation of children without endocrine disease. In this study the influence of corticosteroid therapy on height and skeletal maturation was evaluated in a large population of children with asthma.

\section{MATERIALS AND METHODS}

\section{PATIENTS}

All children had severe asthma and had been referred for care at a residential treatment center in Denver. The study was based on a retrospective evaluation of two population groups: children in residence at the center in 1965 and those admitted in 1970. The ages of both groups (Table 1) ranged between 6 and 15 years, with a mean age of 11 . Most of the patients were Caucasian children from middle income families. The larger number of boys reflects the population at the treatment center.

The initial phase of the study was based on evaluation of height and skeletal maturation at the time of admission in 189 children. The number of subjects in this portion of the study permitted separate evaluation of the data in boys and girls.

The second phase of the study was based on evaluation of the changes in physical development during the period of residential care. For this purpose comparisons were made of height and skeletal ages at the time of admission and discharge in 76 children (49 boys and 27 girls). The duration of residential treatment ranged between 12 and 24 months with an average of 17 months. This portion of the study is largely based on data of children hospitalized during 1965.

\section{EXPERIMENTAL APPROACH}

To reduce bias in interpretation of data, the study was approached first by assessment of skeletal ages from radiographs of the left hand and wrist which had been obtained during the course of routine diagnostic evaluation (22). After the assessment of skeletal ages had been completed, the heights and weights of the patients at the time of the $x$-ray examinations were abstracted from the charts and recorded separately. The patients' charts were then reviewed without regard to the growth data and an assessment was made of the course and severity of the asthma and the history of steroid therapy.

\section{EVALUATION OF SKELETAL DATA}

Skeletal ages were determined by the author through comparison of radiographs of the left wrist with the standards in a 